XIV. Methode fiir eine schnelle Austrocknung von Flaschen, Röhren etc., sowie für eine bequeme Verbindung weiter Röhren mit engen; von Emil Zettnow.

I) $\mathbf{R}_{\text {echt häufig wünscht man eine nicht nur reine, }}$ sondern auch völlig trockene Flasche, Röhre etc. und sehr oft ist eine solche nicht zur Hand. Ich spüle deswegen um innerhalb 1 bis 3 Min. ein Gefäls, sey es klein oder grols, auszutrocknen, dasselbe zuerst mit starkem Alkohol, hierauf mit Aether aus und verjage letzteren durch Einblasen von Luft mittelst des Blasebalges. Es sind zu diesem Zwecke in meinem Laboratorium zwei Flaschen vorhanden, die eine mit etwa $200 \mathrm{CC}$. Alkohol von 95 Proc., die andere mit derselben Menge Aether gefüllt und reicht diese Quantität für mindestens 150 Gefälse aus.

II) Um enge Röhren mit weiten zu verbinden, ein Fall, welcher sehr häufig vorkommt, kann man die weitere Röhre in eine Spitze ausziehen und dieselbe alsdann so weit abbrechen, dafs sie der engeren Röhre an Dicke gleichkommt.

\title{
XV. Tetronerythrin, ein neuer organischer
} Farbstoff; vom Badearzt Dr. Wurm.

(Mitgetheilt vom Hrn. Verf. aus v. Siebold's und Kölliker's Zeitschr. f. wissensch. Zoologie 1871.)

1) ie Wiener „Jagdzeitung “ (1868) enthält die gelegentliche Notiz, dal's die "Rose" (der rothe warzige Fleck über den Augen) des Auer - und Birkhahnes, mit einem weifsen Tuche gerieben, auf das Schönste abfärbe, wozu 